\title{
Applications of lagrangian dispersion modeling to the analysis of changes in the specific absorption of elemental carbon
}

\author{
J. C. Doran ${ }^{1}$, J. D. Fast ${ }^{1}$, J. C. Barnard ${ }^{1}$, A. Laskin ${ }^{1}$, Y. Desyaterik ${ }^{1}$, and M. K. Gilles ${ }^{2}$ \\ ${ }^{1}$ Pacific Northwest National Laboratory, P.O. Box 999, Richland, Washington, 99354, USA \\ ${ }^{2}$ Lawrence Berkeley National Laboratory, Berkeley, CA, USA
}

Received: 25 September 2007 - Published in Atmos. Chem. Phys. Discuss.: 19 October 2007

Revised: 17 January 2008 - Accepted: 12 February 2008 - Published: 7 March 2008

\begin{abstract}
We use a Lagrangian dispersion model driven by a mesoscale model with four-dimensional data assimilation to simulate the dispersion of elemental carbon (EC) over a region encompassing Mexico City and its surroundings. The region was the study domain for the 2006 MAX-MEX experiment, which was a component of the MILAGRO campaign. The results are used to identify periods when biomass burning was likely to have had a significant impact on the concentrations of elemental carbon at two sites, T1 and T2, downwind of the city, and when emissions from the Mexico City Metropolitan Area (MCMA) were likely to have been more important. They are also used to estimate the median ages of EC affecting the specific absorption of light, $\alpha_{\mathrm{ABS}}$, at $870 \mathrm{~nm}$ as well as to identify periods when the urban plume from the MCMA was likely to have been advected over T1 and T2. Median EC ages at T1 and T2 are substantially larger during the day than at night. Values of $\alpha_{\mathrm{ABS}}$ at T1, the nearer of the two sites to Mexico City, were smaller at night and increased rapidly after mid-morning, peaking in the mid-afternoon. The behavior is attributed to the coating of aerosols with substances such as sulfate or organic carbon during daylight hours, but such coating appears to be limited or absent at night. Evidence for this is provided by scanning electron microscopy images of aerosols collected at the sampling sites. During daylight hours the values of $\alpha_{\mathrm{ABS}}$ did not increase with aerosol age for median ages in the range of $1-4 \mathrm{~h}$. There is some evidence for absorption increasing as aerosols were advected from $\mathrm{T} 1$ to $\mathrm{T} 2$ but the statistical significance of that result is not strong.
\end{abstract}

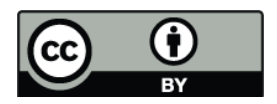

Correspondence to: J. D. Fast (jerome.fast@pnl.gov)

\section{Introduction}

It is generally acknowledged that as soot particles age, their mixing state evolves from an external to an internal one through processes such as heterocoagulation or condensation (e.g., Jacobson and Seinfeld, 2004), and the specific absorption $\alpha_{\mathrm{ABS}}$ (absorption per unit mass) will increase (Fuller et al., 1999; Bond et al., 2006.) It is important to specify appropriate values of $\alpha_{\mathrm{ABS}}$ for use in global climate models, but there is still considerable variation in the values that have been proposed. Bond and Bergstom (2006) concluded that $\alpha_{\mathrm{ABS}}$ for freshly emitted soot particles has a value of $7.5 \pm 1.2 \mathrm{~m}^{2} \mathrm{~g}^{-1}$ at $550 \mathrm{~nm}$, but direct measurements in the field of the rates and effects of aging and coating have been difficult to achieve.

One approach has been to make comparisons of optical properties of soot at a single site at two different times of day, e.g., in the early morning when fresh emissions from traffic are likely to dominate the aerosol mix, and later in the afternoon when a mixture of fresh and more aged particles is likely to be present. The sources and ages of the various components of the mixture may vary widely, however, and efforts to explicitly characterize the ages of the mixture are not usually made. Several investigations of this type have been done in the Mexico City region, which is the location of interest for this study. Johnson et al. (2005) showed that soot can undergo significant coating and evolve into an internally mixed state in only a few hours. In contrast, Mallet et al. (2004) concluded that single scattering albedo measurements in an industrial region of France were more consistent with externally mixed aerosols rather than internally mixed ones. Baumgardner et al. (2000) measured time series of size distribution, scattering and absorption coefficients, and bulk chemical composition of aerosols at a mountain location near Mexico City and related the variations to the meteorological conditions. Baumgardner et al. (2007) measured variations in $\alpha_{\mathrm{ABS}}$ and in the coating of light absorbing carbon (LAC)

Published by Copernicus Publications on behalf of the European Geosciences Union. 


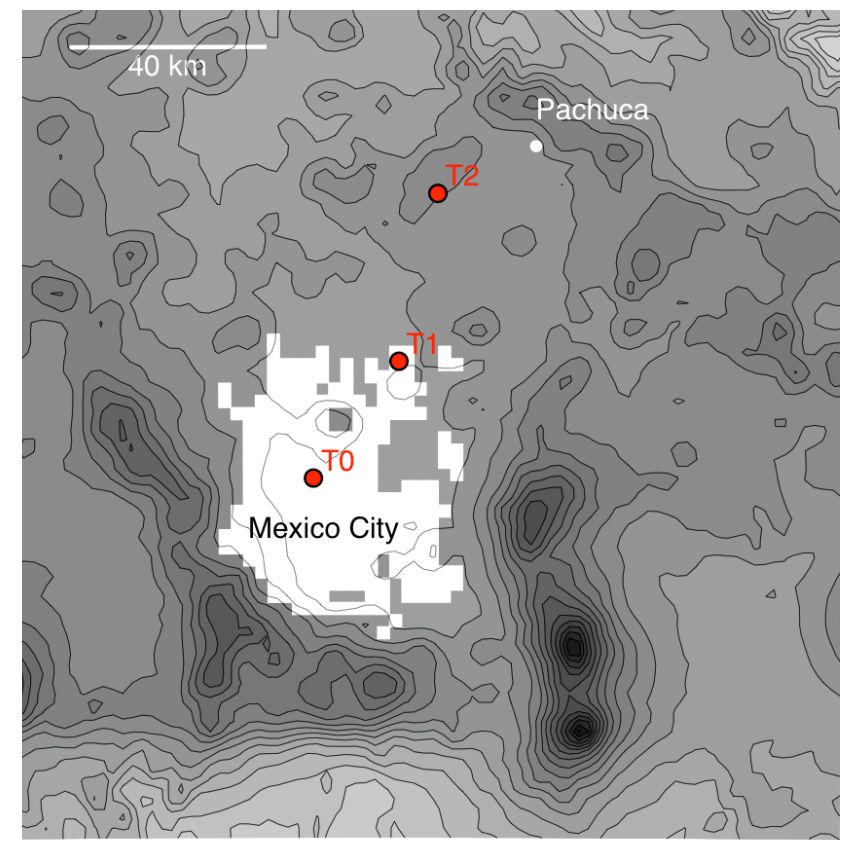

Fig. 1. Map of the study area, including the locations of the sampling sites T0, T1, and T2 and the extent of the Mexico City Metropolitan Area (MCMA). Topography contour intervals are $200 \mathrm{~m}$.

at an urban location in Mexico City. They found that $\alpha_{\mathrm{ABS}}$ changed relatively little during the day, reaching its minimum values when the LAC mass reached its peak around 08:00 LST.

Another approach to the study of aging effects on $\alpha_{\mathrm{ABS}}$ has been to measure soot properties at several sites that are likely to be characterized by particles with different ages, but actual ages are not normally estimated (e.g., Burtscher et al., 1993). Still another approach involves Lagrangian sampling in which an air parcel containing soot is followed from its source to some downwind location, monitoring the mixing state and optical properties of the soot en route. This may be straightforward for point sources (e.g., biomass burning) but can be problematic for more dispersed sources such as a large urban area or when additional sources contribute to the contents of the air parcel en route. Moteki et al. (2007) found that black carbon became internally coated on a time scale of $12 \mathrm{~h}$ in an urban plume downwind of Nagoya, Japan.

Riemer et al. (2004) used meteorological, chemical, and aerosol modeling to simulate the aging of diesel soot and study its evolution from an external to an internal mixture for summer conditions in southwestern Germany. They found that the time scale for the aging process was as short as a few hours during the day and was considerably longer at night, but no estimates of the effect on $\alpha_{\mathrm{ABS}}$ were discussed. Comparisons of aerosol residence times in the atmosphere using this scheme with times from other aging schemes in an atmospheric general circulation model are described by Croft et al. (2005).
A complementary approach to these methods, which we describe in this paper, is to make use of a mesoscale model incorporating four-dimensional data assimilation to help interpret results from field measurements of $\alpha_{\mathrm{ABS}}$. In March of 2006 we made measurements of $\alpha_{\mathrm{ABS}}$ at two sites, labeled $\mathrm{T} 1$ and $\mathrm{T} 2$ and separated by approximately $35 \mathrm{~km}$, downwind of Mexico City. If the time scale for the coating of soot is only a few hours, we would expect that this separation would be sufficient to result in a significant change in $\alpha_{\mathrm{ABS}}$ between $\mathrm{T} 1$ and $\mathrm{T} 2$; if the time scale is on the order of $12 \mathrm{~h}$ or more, the changes would be negligible. The T1-T2 measurements were part of the MAX-Mex (Megacity Aerosol Experiment in Mexico City; http://www.asp.bnl. gov/MAX-Mex.html) component of the MILAGRO (Megacity Initiative: Local and Global Research Observations; http: //www.eol.ucar.edu/projects/milagro/) field campaign. MILAGRO was designed to follow the downwind transport of the urban plume emanating from Mexico City and its surroundings and to study the transformation of gases and aerosols over scales ranging from $10 \mathrm{~s}$ of $\mathrm{km}$ to $1000 \mathrm{~km}$ and more. The MAX-Mex campaign focused on aerosols on local to regional scales. A description of the T1-T2 campaign and some preliminary results have been given in Doran et al. (2007) and Doran (2007), so only a brief summary of it is provided below.

Figure 1 shows a map of the study area, including the locations of the T1 and T2 sampling sites, the location of a third sampling site in an industrial area with heavily trafficked roads closer to the city center, T0, and the extent of the Mexico City Metropolitan Area (MCMA). Sunset Laboratory Organic and Elemental Carbon (OCEC) analyzers (Birch and Cary, 1996) were deployed at $\mathrm{T} 1$ and $\mathrm{T} 2$, as were photoacoustic absorption spectrometers (PASs) operating at a wavelength of $870 \mathrm{~nm}$ (Arnott et al., 1999, 2003); the data from these instruments were combined to determine the specific absorption $\alpha_{\mathrm{ABS}}$ at hourly intervals at each site. Radar wind profilers provided wind information at $\mathrm{T} 0, \mathrm{~T} 1$, and $\mathrm{T} 2$, and radiosondes that measured temperature and humidity were released at $\mathrm{T} 1$ and $\mathrm{T} 2$. A lidar at $\mathrm{T} 1$ was used to help estimate mixed layer depths from aerosol backscatter data.

In an earlier study, Doran et al. (2007) tentatively identified "transport periods" using the wind profiler data at T1 to select times when computed trajectories of air parcels passing over T1 were likely to have originated in the MCMA and subsequently passed near T2 within four hours of leaving $\mathrm{T} 1$. The median value of $\alpha_{\mathrm{ABS}}$ at T2 was slightly higher than at T1 for those periods, but a Mann-Whitney test (Mann and Whitney, 1947) showed that the difference was only significant at the $15 \%$ level. During the course of the analysis for that study, however, it was realized that sources of EC other than those in the MCMA alone were likely to be important, especially at T2. This conclusion was based on field observations and on preliminary numerical modeling that simulated trajectories from both anthropogenic and biomass burning sources. Thus, in characterizing the changes in $\alpha_{\mathrm{ABS}}$, a 
division of data into those collected during transport periods using the criteria above and those collected during other times is likely to have been an over-simplification.

Accordingly, for this paper we have extended our analysis to include a number of new features. We used a mesoscale model incorporating data assimilation to determine wind fields for several weeks, including a 12-day period (15-27 March) when the PAS and OCEC data recovery at T1 and T2 was most successful. We used emissions inventories for the MCMA region, non-MCMA anthropogenic sources, and biomass burning and a Lagrangian particle dispersion model to estimate the amount of black carbon injected into the atmosphere and the amount contributed by each source type at the T1 and T2 sites. Results from such a model can be used in several ways, depending on the available data. For example, we identified periods when contributions from the MCMA were important and other periods when biomass burning was a major source. The diel variations of $\alpha_{\mathrm{ABS}}$ may then be determined during periods when one or the other of these two components dominates. The ages of the aerosols contributing to the measured absorption at a site can be calculated so that variations of $\alpha_{\mathrm{ABS}}$ with the age of the aerosol can be estimated. Finally, the model can be used to identify periods when the MCMA plume is likely to have passed over the $\mathrm{T} 1$ and $\mathrm{T} 2$ sites. The differences between measured values of $\alpha_{\mathrm{ABS}}$ at the two sites under these conditions can then be calculated from the data. Model details are provided in the following sections, followed by our results and a discussion.

We use the terms soot, black carbon, and elemental carbon interchangeably in this paper. This is done for convenience during the discussions to follow but we are aware that these terms are not actually equivalent (Andreae and Gelencsér, 2006). In particular, the data we use in this paper are elemental carbon concentrations, measured by a thermal-optical method, and absorption at $870 \mathrm{~nm}$, measured with PASs, of light absorbing carbon. At this wavelength the contribution from organics and dust should be very small (Jacobson, 1999; Sokolik and Toon, 1999; Sato et al., 2003; Kirchstetter et al., 2004). The data from these two instruments were combined to provide values of $\alpha_{\mathrm{ABS}}$. Note that many previous measurements of $\alpha_{\mathrm{ABS}}$ have been reported for a wavelength of $550 \mathrm{~nm}$. Thus, when comparing our values with previous ones it will be necessary to extrapolate from our measurements to values expected at the shorter wavelength.

\section{Modeling}

The Weather Research and Forecasting (WRF) model (Skamarock et al., 2005) was used to simulate the local, regional, and synoptic meteorological conditions during the MILAGRO field campaign. A 24-day simulation period that started at 06:00 UTC on 6 March was chosen to include three days of "spin-up" prior to the beginning of surface measurements, which were obtained at the T1 and T2 sites beginning on 9
Table 1. Parameterizations employed by WRF in this study.

\begin{tabular}{ll}
\hline Atmospheric Process & Model Option \\
\hline Longwave radiation & RRTM (Mlawer et al., 1997) \\
Shortwave radiation & Goddard (Chou and Suarez, 1994) \\
Surface layer & Monin-Obukov \\
Land surface & Noah (Chen and Dudhia, 2001) \\
Boundary layer & YSU (Hong et al., 2006) \\
Cumulus clouds & turned off \\
Cloud microphysics & Purdue Lin scheme (Chen and Sun, 2002)
\end{tabular}

March. Two domains were employed: an outer domain encompassing most of Mexico and the surrounding ocean with a grid spacing of $12 \mathrm{~km}$, and a $205 \mathrm{~km} \times 157 \mathrm{~km}$ inner domain encompassing central Mexico with a grid spacing of $3 \mathrm{~km}$. The initial and boundary conditions for WRF were based on the National Center for Environmental Prediction's Global Forecast System analyses available every six hours. Table 1 lists the specific parameterizations used by WRF in this study.

Four-dimensional data assimilation (4DDA) that employed an observational nudging technique (Liu et al., 2006; Stauffer and Seaman, 1994) was used to constrain the meteorology during the simulation period. Wind speed and direction data were obtained to heights of approximately $4000 \mathrm{~m}$ from radar wind profilers at $\mathrm{T} 0, \mathrm{~T} 1, \mathrm{~T} 2$, and Veracruz ( $\sim 315 \mathrm{~km}$ east of Mexico City). Wind speed, direction, temperature, and humidity values were extracted from the 00:00, 06:00, 12:00, and 18:00 UTC soundings at Mexico City, Acapulco ( $\sim 300 \mathrm{~km}$ south of Mexico City) and Veracruz. The spatial influence of the measurements was limited to a horizontal distance of $30 \mathrm{~km}$ near the surface so that the complex circulations resulting from terrain forcing were not overly smoothed. Because most of the measurements were located between Mexico City and T2, the meteorological conditions were constrained only over a small portion of the modeling domain.

Figure 2 show an example of the measured wind fields at two heights at the T1 site, along with the model values with and without data assimilation. Winds from a southwesterly direction may transport material from the MCMA over $\mathrm{T} 1$ and $\mathrm{T} 2$, and the figure shows that these conditions are often found at $\sim 2100 \mathrm{~m}$ but less consistently at $\sim 400 \mathrm{~m}$ AGL (above ground level). The wind directions closer to the surface are more variable than higher up, reflecting the strong influence of localized thermal and topographic forcing. Throughout the simulation period the model does a generally good job of reproducing the observations even without data assimilation, but there are some improvements when assimilation is carried out, as expected. At the higher elevations the agreement between measured and modeled speeds is somewhat better than at the lower ones. We call attention 

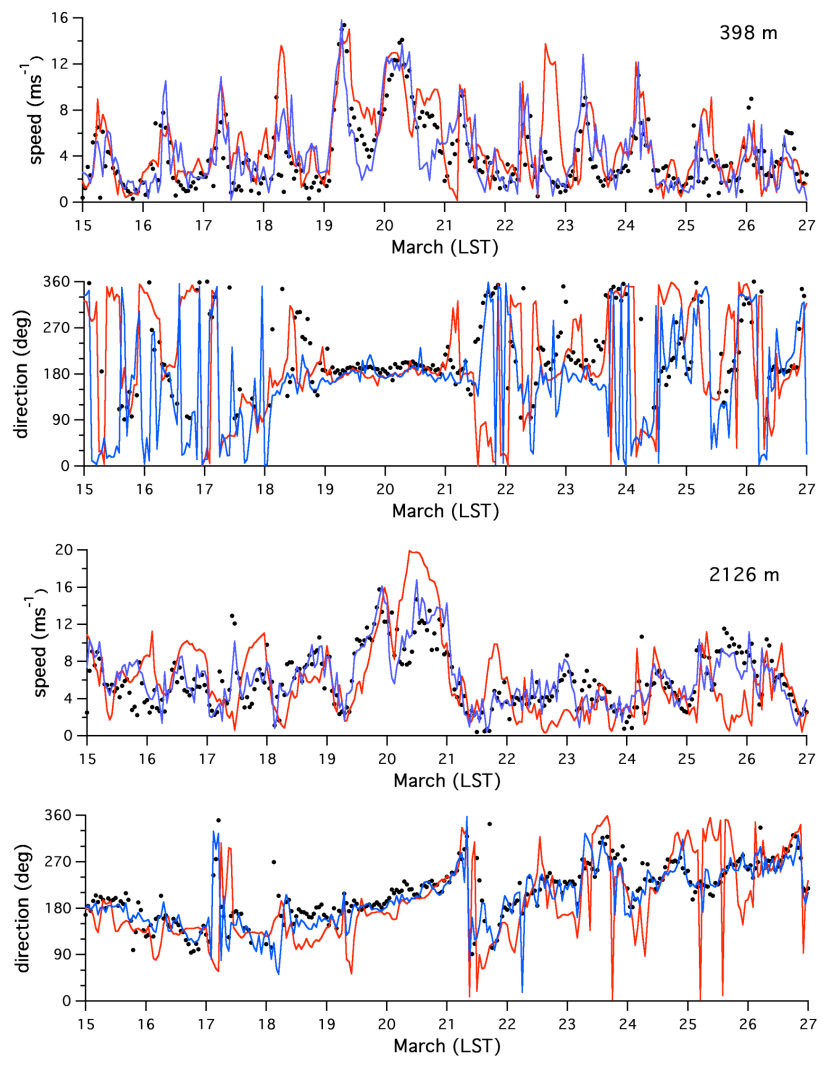

Fig. 2. Measured (dots) and modeled (lines) wind speeds and directions at T1. Model values are shown without (red) and with (blue) data assimilation.

to the period of 18-21 March when winds from the south southwest prevailed throughout the lowest $2 \mathrm{~km}$ or more. This time period appeared to be particularly favorable for transport of the MCMA plume over T1 and T2 (e.g., Fig. 9 in this paper and trajectories shown in Doran et al. (2007)), and the modeled winds agree especially well with the data. The comparisons between measured and modeled winds at T2 (not shown) gave similar good agreement.

The transport and turbulent mixing of tracers was simulated using the FLEXPART Lagrangian particle dispersion model (Stohl, 2005). FLEXPART was originally designed to use meteorological fields produced by global models, but we adapted it to use meteorological fields produced by WRF and to have turbulent mixing consistent with mesoscale applications.

In this study, meteorological fields at 30-min intervals were used to drive FLEXPART. Passive tracer particles were released to mimic the spatially and temporally varying emission rates of black carbon. Three types of sources were defined: 1) anthropogenic black carbon released within the Mexico Valley (MCMA sources), 2) anthropogenic black carbon released outside of the Mexico Valley, and 3) black carbon released from biomass burning sources. An-

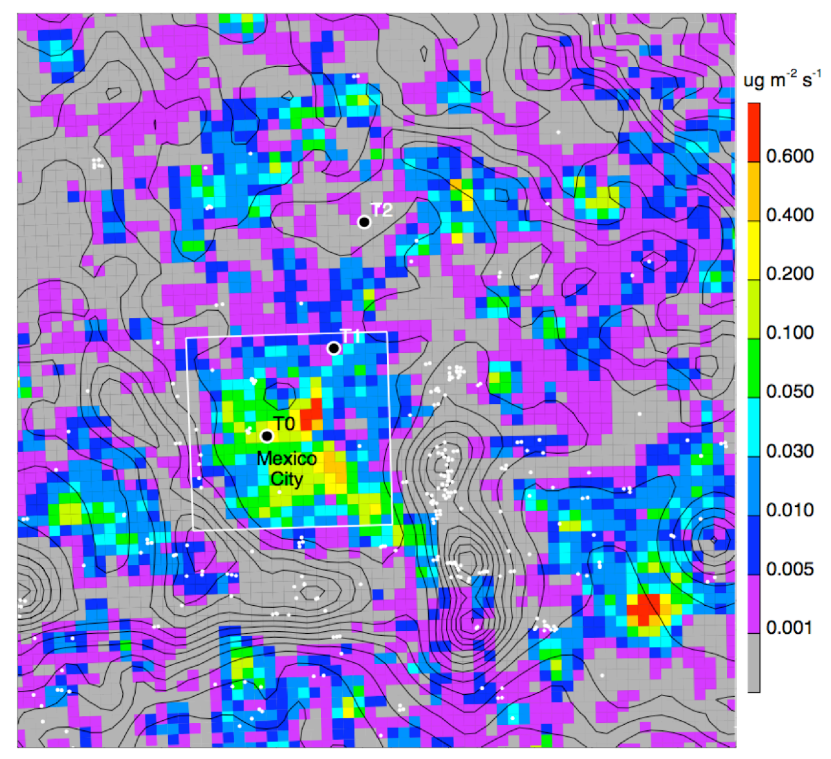

Fig. 3. Map of anthropogenic black carbon emission rates used for simulations. White dots correspond to biomass burning sources from MODIS during March and the white box outlines the MCMA source region. Black contour intervals are $200 \mathrm{~m}$.

thropogenic emission rates were estimated using the 1999 National Emission Inventory (NEI; http://www.epa.gov/ttn/ chief/net/1999inventory.html). In the NEI inventory, emission ratios of $\mathrm{BC} / \mathrm{PM}_{2.5}$ averaged over urban and suburban areas of Phoenix, Houston, and Dallas are given as $0.127,0.222$, and 0.124 , respectively, with the high value for Houston perhaps related to the petrochemical facilities concentrated there. The NEI inventory contains emission rates of $\mathrm{PM}_{2.5}$ over Mexico (http://www.epa.gov/ttn/chief/ net/mexico.html) that are not speciated, but an investigation for Mexico City (Miguel Zavala, private communication) has suggested a value of 0.18 for $\mathrm{BC} / \mathrm{PM}_{2.5}$ in that region. We settled on a value for the black carbon released of 0.15 of the total $\mathrm{PM}_{2.5}$ mass, which is an intermediate value among the various estimates we had available. Biomass burning emission rates were derived from MODIS fire count data and vegetation type as described by Wiedinmyer et al. (2006). Biomass burning emission rates varied diurnally with the lowest values around sunrise and peak values during the late afternoon. Figure 3 shows a map of the study area with the anthropogenic emission rates of black carbon for the MCMA and non-MCMA area as well as the locations of biomass burning sites from the MODIS data.

The median ages (from the time of release) of the tracer particles in boxes $5 \mathrm{~km}$ on a side at T1 and T2 were computed, as were the fractions of the particles in each box originating from each type of source. The output from the model was then used to identify and select periods for analysis, based on factors such as median particle age, fraction of the EC arising from MCMA sources, and transport of the 

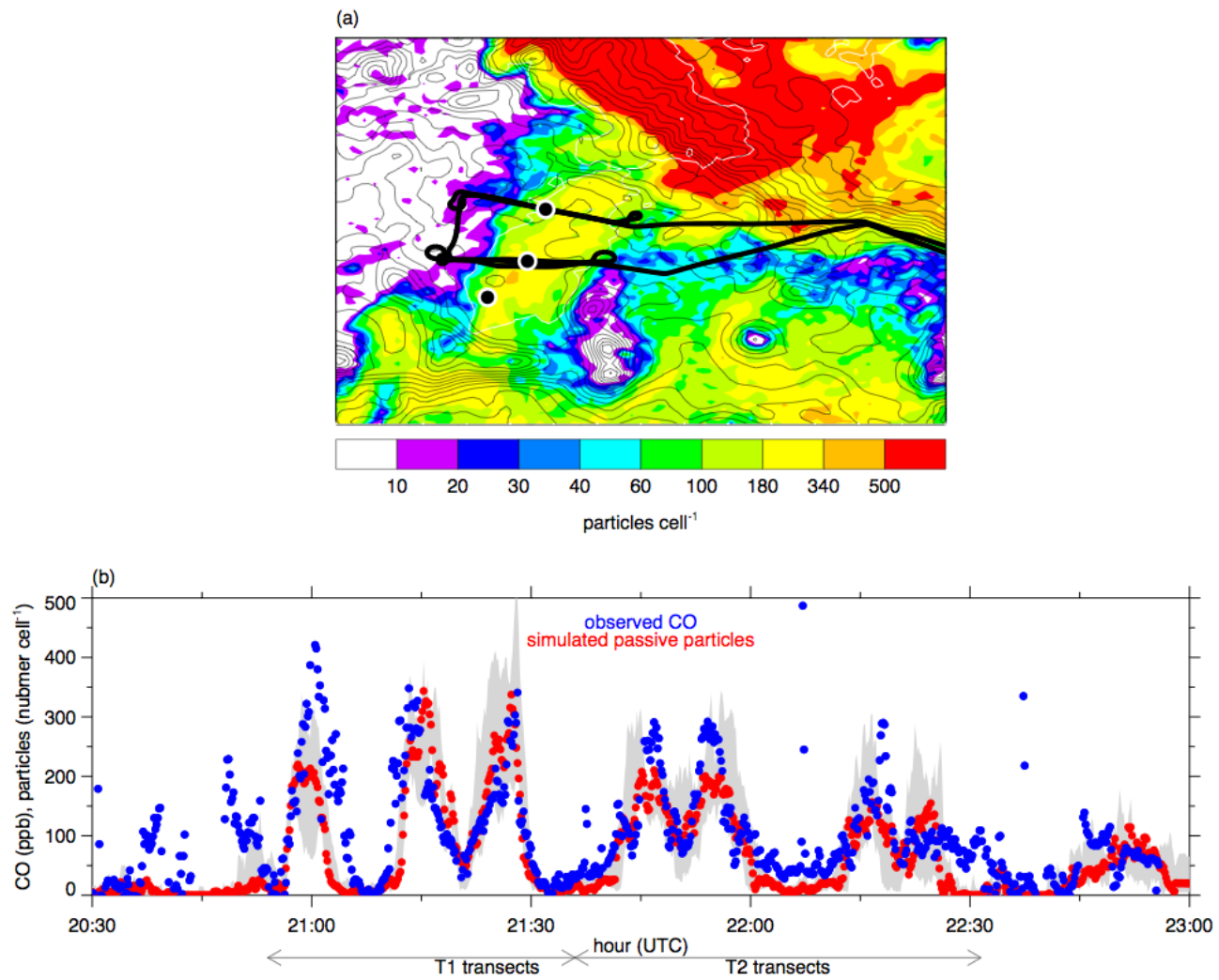

Fig. 4. (a) Contour plot of particle concentrations at $900 \mathrm{~m}$ AGL at 15:30 LST on 20 March, and flight paths of G-1 aircraft over T1 and T2 during the afternoon. (b) Measured CO mixing ratios on the G-1 (blue dots), simulated tracer particle concentrations at the G-1 locations interpolated to the times the G-1 crossed those locations (red dots), and range of simulated particle concentrations at each location during the G-1 flights (gray shading).

MCMA plume between T1 and T2. Subsequent tests with boxes $10 \mathrm{~km}$ on a side gave results similar to those with $5 \mathrm{~km}$ sides.

\section{Model evaluation}

3.1 Comparison of tracer particle concentrations with aircraft observations

DOE's Gulfstream-1 (G-1) aircraft flew a number of missions over the T1 and T2 sites during the course of the experiment, and the data from some of those flights can be used to help assess the performance of the model. The top panel of Fig. 4 shows the tracks of one of those flights on the afternoon of 20 March overlaid on a contour map of simulated particle concentrations at an elevation of $900 \mathrm{~m}$ AGL. Flight tracks at three heights over T1 and T2 are stacked on top of each other in the figure. The bottom panel shows the observed CO concentrations (blue dots) that we used as a surrogate for black carbon (Baumgardner et al., 2002), which was not measured on the G-1. Results for the three sampling heights over T1 and T2 are shown, with nominal altitudes of 2070, 1460, and $860 \mathrm{~m}$ AGL over T1 and 600, 1210, and $1830 \mathrm{~m}$ AGL over T2. The red dots are the model values at the G-1 locations interpolated to the times the G-1 crossed those locations, and the gray shading denotes the range of simulated values at each location during the whole G-1 sampling time period. Although all of the details are not replicated, the model does a reasonably good job of simulating the position and width of the anthropogenic plume northeast of Mexico City.

\subsection{Comparison of tracer particle concentrations with sur-} face EC measurements

Figure 5 shows time series of the EC concentrations measured at the $\mathrm{T} 1$ site. It also shows the total number of tracer particles in boxes $5 \mathrm{~km}$ on a side centered at T1. A lowess filter (Cleveland, 1979) with a $\sim 6$-h smoothing window is drawn through each of the series to highlight the more regular variations of the series, especially the diel variations of EC. The simulated tracer particle counts show temporal variations that are similar to those found for the EC values. The model generally captures the timing of the diel fluctuations 

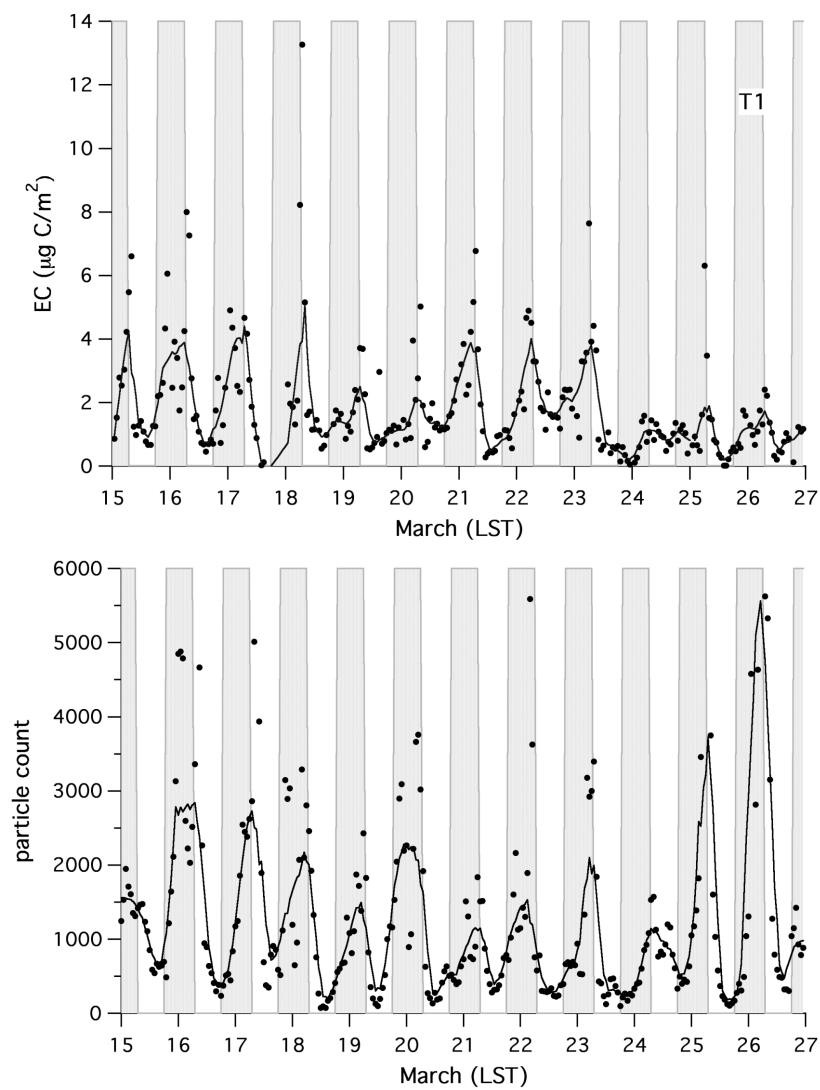

Fig. 5. Time series of the EC concentrations measured at the $\mathrm{T} 1$ site, and the total number of tracer particles in boxes $5 \mathrm{~km}$ on a side centered at $\mathrm{T} 1$. The line is a lowess filter through the data. Nighttime periods are indicated by the shaded areas.

but it has more difficulty with the magnitudes of the signal. The largest discrepancies occur on 25 and 26 March with two major peaks in the particle counts; although they correspond to peaks in the EC concentrations, the latter are considerably less prominent. We speculate that the observed EC may have been reduced by precipitation scavenging during rainy episodes in the last several days of this period, an effect that is not captured in the numerical simulations.

Figure 6 shows the corresponding behavior of EC and tracer particles at $\mathrm{T} 2$. The EC variations do not have the same regularity in diel trends as those found at $\mathrm{T} 1$, nor do the variations in the particle counts show the same degree of fidelity to the EC variations as was found for T1. The EC concentrations for 18-23 March are generally higher than for the rest of the period, reflecting the prevalence of favorable wind conditions that bring the MCMA plume and material from biomass burning over $\mathrm{T} 2$ during much of that time, and there are major peaks in the tracer particle counts on 18,20, and 22 March. The particle peaks drop off too quickly, however, so that the broad maximum in the EC concentration time series is not well captured by the particle simulations.
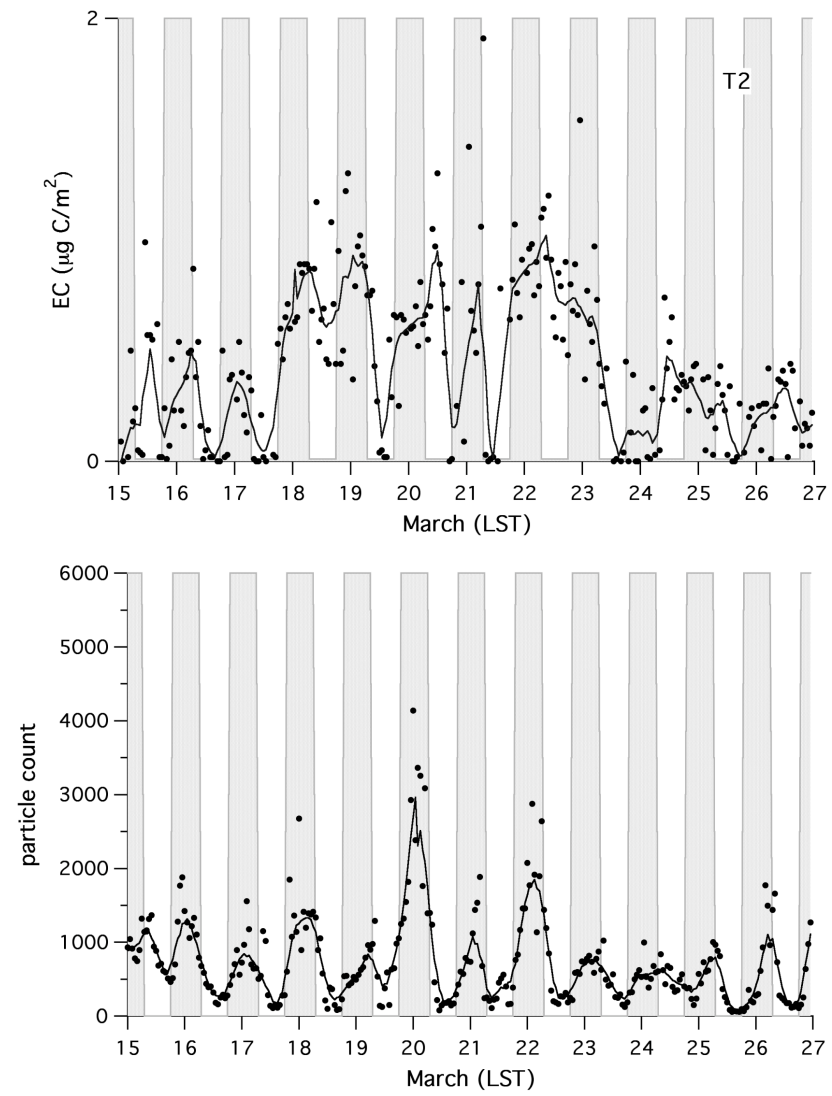

Fig. 6. As in Fig. 5 except for the T2 site.

There are a number of factors that may contribute to the poorer performance of the model in simulating EC concentrations at T2. First, the simulated dispersion over the modeling domain is necessarily imperfect. Errors in the simulated wind speeds or directions, the depth of the boundary layer, or the representations of the turbulent mixing can all lead to errors in the dispersion patterns. As noted earlier, the agreement between measured and modeled speeds is better at higher elevations than closer to the surface, which may account for the better agreement with the G-1 observations shown in Fig. 4. Moreover, the emission inventories for MCMA and non-MCMA anthropogenic sources and the biomass burning sources have their own uncertainties, so that the strength, location, and timing of important sources may not be adequately represented. A comparison of the time series of observed values of $\mathrm{CO}$ and $\mathrm{EC}$ with simulated values obtained from the WRF-Chem model (Fast et al., 2006) for T1 is shown in Fig. 7. The model does a reasonable job of capturing the temporal variations of the $\mathrm{CO}$ and EC but the magnitude of the simulated EC is typically too small. This suggests that there are likely more uncertainties in EC emission rates than $\mathrm{CO}$ emission rates from anthropogenic and biomass burning sources, because both quantities are equally affected by the predicted meteorology. 


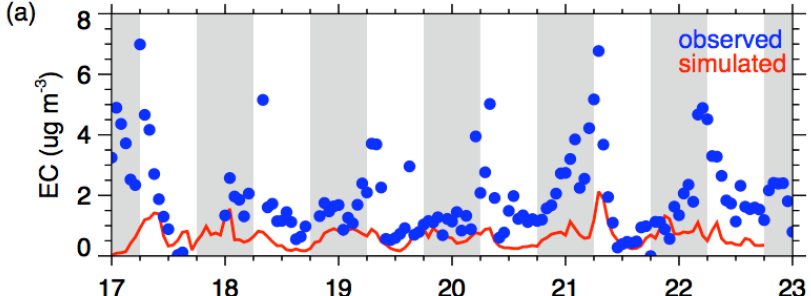

(b)

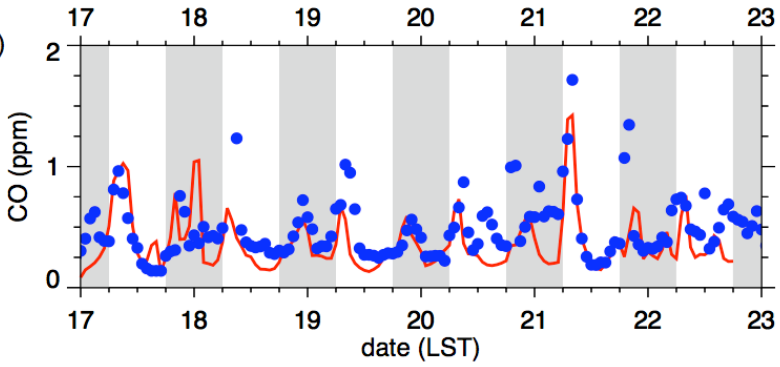

Fig. 7. Time series of observed (blue dots) and simulated (red lines) EC and CO concentrations at T1 for the period 17-23 March.

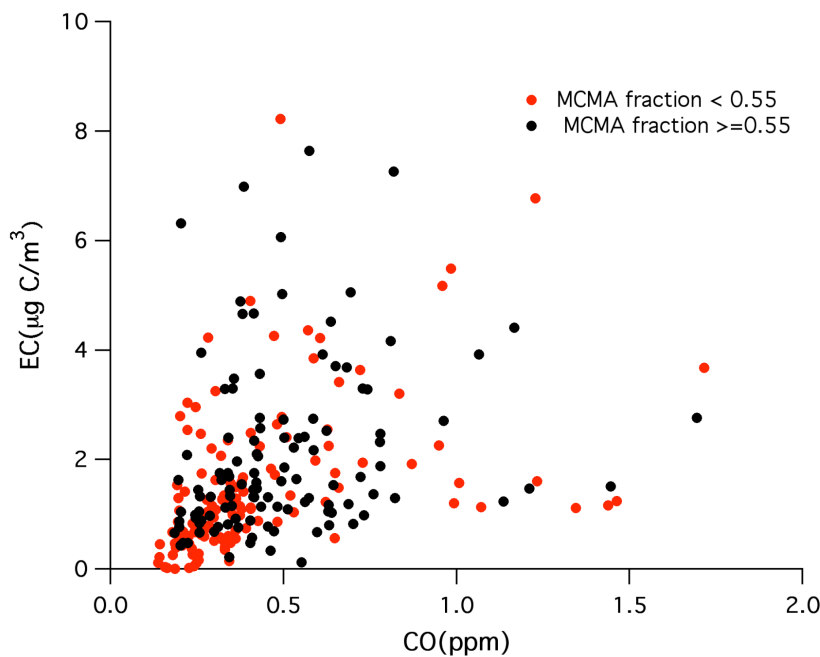

Fig. 8. Variation of EC concentrations with $\mathrm{CO}$ concentration at $\mathrm{T} 1$ for conditions when the MCMA fraction is greater than or equal to 0.55 (black dots) or less than 0.55 (red dots).

In addition, $\mathrm{EC}$ concentrations at $\mathrm{T} 2$ are generally smaller than at $\mathrm{T} 1$ and biomass burning is a more important source of EC (cf. Fig. 9), so that even small errors in the biomass burning inventory can result in considerable uncertainty in calculated EC concentrations at T2. As a result, more care must be taken when analyzing the $\mathrm{T} 2$ data compared to that needed for the $\mathrm{T} 1$ data.

\subsection{Comparisons of EC and CO measurements}

In his review of this work, Baumgardner suggested that an examination of the slope of the EC-CO relationship might be able to distinguish occasions when the majority of the EC
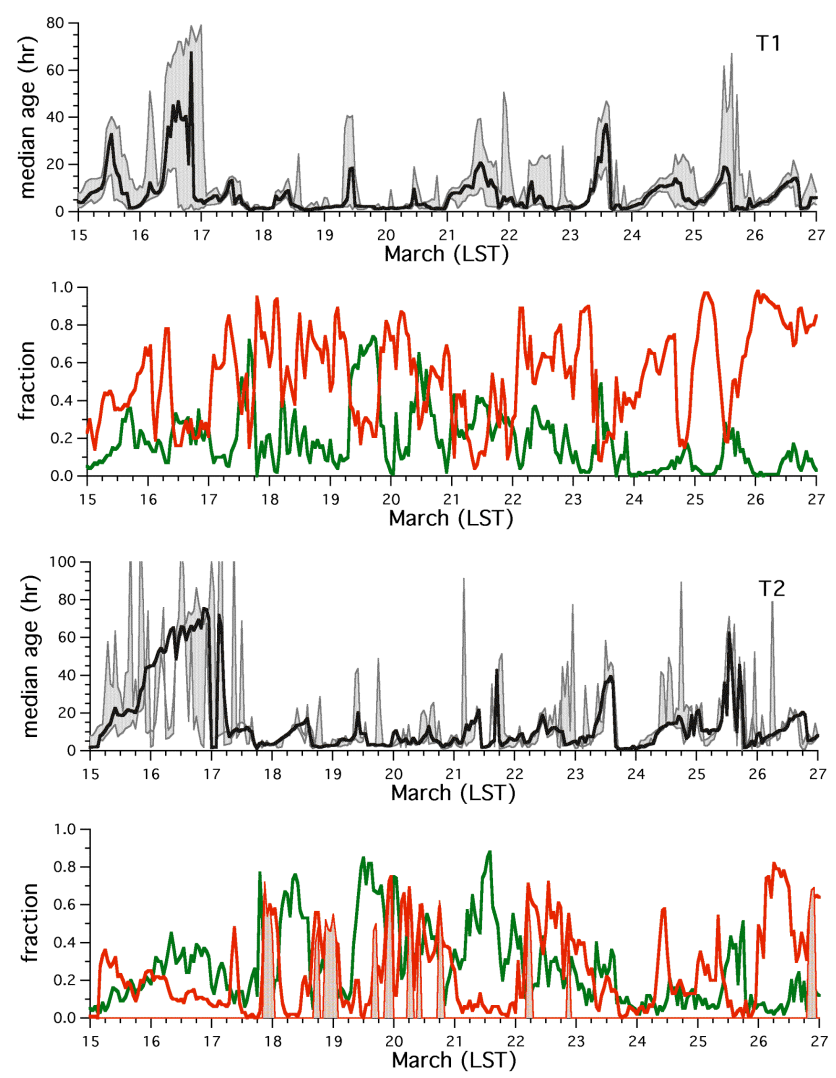

Fig. 9. Computed median ages of collections of simulated tracer particles and the computed fractions of the particles at each site that are attributable to MCMA (red lines) and to biomass burning (green lines) sources at T1 (upper two panels) and T2 (lower two panels). The filled areas in the plots of median ages indicate the 25 th to 75 the percentile range of values. The filled areas in the bottom panel correspond to times identified as transport periods with the MCMA fraction $\geq 0.4$ and the median particle age $\leq 6 \mathrm{~h}$.

was coming from Mexico City from those when the EC values were heavily influenced by biomass burning. Figure 8 shows such a comparison of measured CO and EC. In the figure the black points correspond to periods when the fraction of tracer particles at $\mathrm{T} 1$ attributable to MCMA sources was 0.55 or larger, while the red points were obtained when this fraction was less than 0.55 . The value of 0.55 was chosen because it is the median value of the MCMA fraction for the complete analyzed time series. We are unable to discern any clear separation of the two sets of points in the figure, and we suggest the following reason for the observed scatter. In the emissions inventories available to us, the CO-EC relationship varies among different sectors of the city, and the CO-EC relationship for various biomass sources also varies. Thus, while a good CO-EC correlation might be obtained closer to local sources within the city, a downwind site like $\mathrm{T} 1$ is influenced by a variety of sources with differing COEC slopes. Thus, a clear separation of MCMA-dominated 


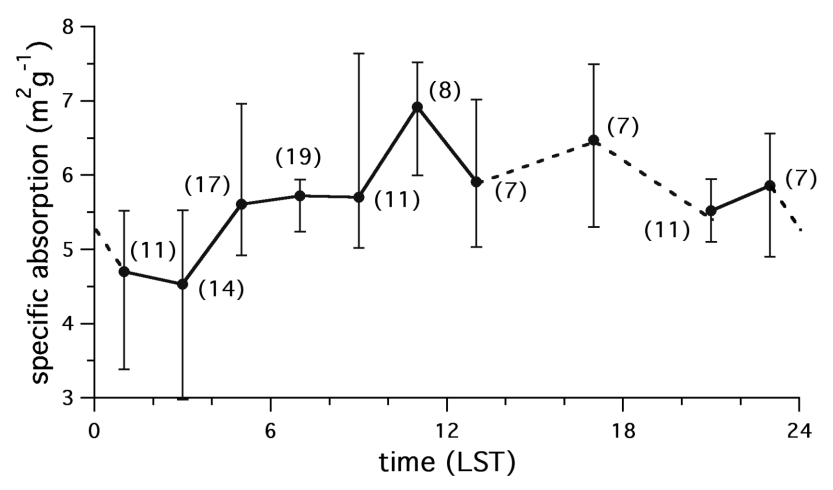

Fig. 10. Variation of median specific absorption (at $870 \mathrm{~nm}$ ) at $\mathrm{T} 1$ with time when MCMA fraction $\geq 0.5$ and median age $<12 \mathrm{~h}$. Numbers in parentheses are the number of samples in each 2-h time bin used to compute the median values. Dashed lines indicate missing values and vertical lines indicate 25 th and 75 th percentile values.

and biomass burning-dominated periods is less likely to be evident in the CO-EC slopes.

\section{Results and discussion}

\subsection{Particle ages}

Figure 9 shows time series of the computed median ages of tracer particles at $\mathrm{T} 1$ and $\mathrm{T} 2$. Here, age means the time from the emission of the tracer particle until its arrival at one of the two sites. Also shown in the figure are the computed fractions of the particles at each site that are attributable to MCMA and to biomass burning sources. Given the ability of the tracer simulations to mimic the EC concentrations, we can expect the ages and the MCMA and biomass fractions to be reasonably accurate at $\mathrm{T} 1$ but subject to more uncertainty at T2. Despite this uncertainty, it is clear that the median ages of the tracer particles at $\mathrm{T} 1$ are usually smaller than those at $\mathrm{T} 2$, reflecting the proximity of the MCMA to $\mathrm{T} 1$ and the dominant role that the MCMA emissions have at the T1 site. For the 15-27 March period at T1, the median ages were small at night $(\sim 1-3 \mathrm{~h})$ and increased during the early afternoon $(\sim 11 \mathrm{~h})$. T2 showed similar trends but the median ages ranged between approximately 3 and $14 \mathrm{~h}$.

\subsection{Biomass burning}

From Fig. 9 it appears that biomass burning occasionally contributed a significant portion of the elemental carbon measured at T1 even thought the primary source of EC was typically the MCMA. At T2 the biomass contribution is more likely to have been the primary one for much of the period. The details of the biomass calculations should also be used with some care, however. In addition to the difficulties associated with simulating the dispersion of EC over the domain described above, the estimation of black carbon emis- sions from biomass burning is also uncertain. Wiedinmyer et al. (2006) discuss some of the limitations of the emissions inventory used for this study, and Yokelson et al. (2007) note that MODIS fire count data may substantially underestimate the number of fires in the Mexico City area during the MILAGRO campaign. Reid et al. (2005) reviewed sources of uncertainty for biomass burning and summarized the large range of emission factors that have been reported in the literature. That problem is exacerbated by investigators' use of different procedures for determining OC and EC fractions in samples analyzed by thermal methods, such as those used in this study. In this context Reid et al. conclude that "results must be treated as semi-quantitative, and the best an investigator can currently hope for is consistency". Thus, while the information provided in Fig. 9 provides a sense of the importance of the contributions from biomass burning, we must also expect some uncertainty in estimates of its effect on either the amount or age of the elemental carbon, especially at $\mathrm{T} 2$.

\subsection{Variations of $\alpha_{\mathrm{ABS}}$ at T1}

We have calculated values of $\alpha_{\mathrm{ABS}}$ for times when the fraction of tracer particles attributable to MCMA sources was equal to or larger than the median MCMA fraction of 0.55, and the median age was $12 \mathrm{~h}$ or less at T1. We choose these values to exclude periods when biomass burning may have been the dominant contributor to the observed EC at this site and to focus on more recent rather than aged emissions. Figure 10 shows the variation with hour of the day of the median values of $\alpha_{\mathrm{ABS}}$ at T1 computed for the period 15-27 March. Because the distributions of specific absorption and age are skewed and can have some large outliers, we prefer to use median values rather than mean values as a more robust indicator of behavior. If fewer than six values were available for a given two-hour block, the median is not displayed. The small sample sizes during the afternoon are attributable in large measure to the limitation we imposed on the median ages of the particles. At night and during the early morning hours, local sources contribute strongly to particle concentrations at T1. In late morning or afternoon, the deepening boundary layer can entrain particles from layers aloft that may originate from more distant or older sources, and the median ages of the particles at $\mathrm{T} 1$ increase rapidly. When we eliminate periods strongly affected by these older particles, the sample size is substantially reduced. Although the sample sizes for the remaining cases are not large, some trends do stand out. Values of $\alpha_{\mathrm{ABS}}$ increase slowly after reaching a minimum in the early morning hours, and then grow further after sunrise as the day progresses. The values then decrease quickly in the early evening and somewhat more slowly thereafter. There is considerable variation during the diel cycle, with the maximum median value of $\alpha_{\mathrm{ABS}}$ about $50 \%$ higher than the minimum. The range of values and the timing of the minima and maxima differ from those reported by Baumgardner 
Table 2. Median values of $\alpha_{\mathrm{ABS}}$ at T1 at $870 \mathrm{~nm}$, in $\mathrm{m}^{2} \mathrm{~g}^{-1}$, as a function of median tracer particle age, for periods when the MCMA fraction of the modeled tracer particle concentrations were $\geq 0.5$. Numbers in parentheses following the sampling times are the number of sample hours in that category.

\begin{tabular}{ccccc}
\hline Age (h) & Sampling time LST (day) & $\alpha_{\mathrm{AB}}$ & Sampling time LST (night) & $\alpha_{\mathrm{AB}}$ \\
\hline $1-2$ & $09: 00-18: 00(5)$ & 7.72 & $21: 00-06: 00(23)$ & 5.04 \\
2 & $11: 00-18: 00(7)$ & 7.07 & $23: 00-06: 00(16)$ & 4.82 \\
$4-6$ & $13: 00-18: 00(1)$ & & $01: 00-06: 00(11)$ & 4.86 \\
\hline
\end{tabular}

et al. (2007), who found that $\alpha_{\mathrm{ABS}}$ increased only slightly during the day, with a minimum occurring at approximately 08:00 LST. Our differences in the temporal behavior of $\alpha_{\mathrm{ABS}}$ may be related to the relative locations of their and our sampling sites. For example, Baumgardner has pointed out in a review of this work that their site was quite close (within $300 \mathrm{~m}$ ) of a significant source of EC, leaving little time for aerosol growth through diffusion or condensation.

For comparisons with previous measurements we extrapolated our values of specific absorption from $870 \mathrm{~nm}$ to $550 \mathrm{~nm}$ using a $\lambda^{-1}$ dependence, which increases our values by a factor of 1.58. For all cases our values average about $9.0 \mathrm{~m}^{2} \mathrm{~g}^{-1}$ during the mid-morning hours (08:0011:00 LST) at T1. This compares reasonably well with the values of 7.4 to $8.1 \mathrm{~m}^{2} \mathrm{~g}^{-1}$ derived by Barnard et al. (2007) from column measurements with a rotating shadowband radiometer in Mexico City in 2003. In contrast, the measurements of Baumgardner et al. (2007) gave values of 4.5$5.0 \mathrm{~m}^{2} \mathrm{~g}^{-1}$, while a value of $7.0 \mathrm{~m}^{2} \mathrm{~g}^{-1}$ was reported earlier by Baumgardner et al. (2002). These values are all consistent with suggestions by Fuller et al. (1999) that $\alpha_{\mathrm{ABS}}$ is not likely to exceed $10 \mathrm{~m}^{2} \mathrm{~g}^{-1}$ except under restrictive conditions not met in the MCMA. Specific reasons for the differences among the various measurements are not known but are probably attributable, at least in part, to the different locations for the measurements. Another possibility is that different measurement techniques contributed to the differences, although Slowik et al. (2007) report good agreement between measurements of black carbon content using a PAS and a Single Particle Soot Photometer, the instrument used by Baumgardner et al. (2007). A number of instrument comparison studies have been conducted in the past (e.g., Sheridan et al., 2005) but have not typically included comparisons between in situ and column measurements of the type described here. Additional side-by-side comparisons of the various techniques in the field would be useful in the future.

We used the mesoscale model results to estimate ages for the aerosols responsible for the absorption at $\mathrm{T} 1$ during both daytime and nighttime. We binned the median ages into bins of $1-2 \mathrm{~h}, 2-4 \mathrm{~h}$, and $4-6 \mathrm{~h}$, and calculated the median absorption for each bin. We selected the time periods during which measurements were made to ensure that aerosols with ages corresponding to each bin were either always in sun- light or always in the dark. For example, for aerosols with median ages of $1-2 \mathrm{~h}$, the sampling times for daylight conditions were 09:00 to 18:00 LST. If sampling times earlier than 09:00 LST had been used, a 2-h old aerosol would have spent part of its life prior to sunrise. For aerosols in the 2 $4 \mathrm{~h}$ bin the beginning sampling time was delayed further until 11:00 LST. The results are shown in Table 2.

The rate of coating of soot and the enhancement of $\alpha_{\mathrm{AB}}$ may be expected to depend on solar radiation and the concentration of condensable species, and these will both vary with time and location during the daylight hours; at night, coagulation may be the more important process (Riemer at al., 2004). Thus, a simple relationship between soot age and a particular value of $\alpha_{\mathrm{AB}}$ should not be expected. From our data we found that the specific absorption values decreased as the median ages of the particles increased from $1-2 \mathrm{~h}$ to $2-4 \mathrm{~h}$, and they did so during both the day and night. There was a negligible subsequent increase in $\alpha_{\mathrm{ABS}}$ for the $4-6 \mathrm{~h}$ bin at night, but only one case in that age category was found for the day. Because of the small sample sizes and the small differences, none of the daytime or nighttime differences in Table 2 are statistically significant at the 5\% level; the differences between daytime and nighttime values for the corresponding age bins are significant at the $5 \%$ level.

Our results do suggest that soot aging and coating proceed quite rapidly during the day and that any increases in absorption after the first hour or so of the aerosol's lifetime are small. Conversely, at night photochemical processing is absent, the aging and coating proceed more slowly, and values of $\alpha_{\mathrm{ABS}}$ are less affected by coating. This is broadly consistent with the observations of Johnson et al. (2005) and the modeling work of Riemer et al. (2004) described earlier. Additional support for this suggestion is provided by electron microscopy analysis of particles collected at the T0, T1 and T2 sites during the 2006 campaign. As an example, Fig. 11 shows a series of scanning electron microscope (SEM) images of particles collected at T0 on 22 March. As indicated by the micrographs, particles in early morning samples are seen as "dry" grey spots with little or no coating. In contrast, particles collected during the late morning or afternoon hours show clear evidence of organic coating. This coating - apparent in the images as the darker substance surrounding the grey particles - is likely photo-chemically formed 

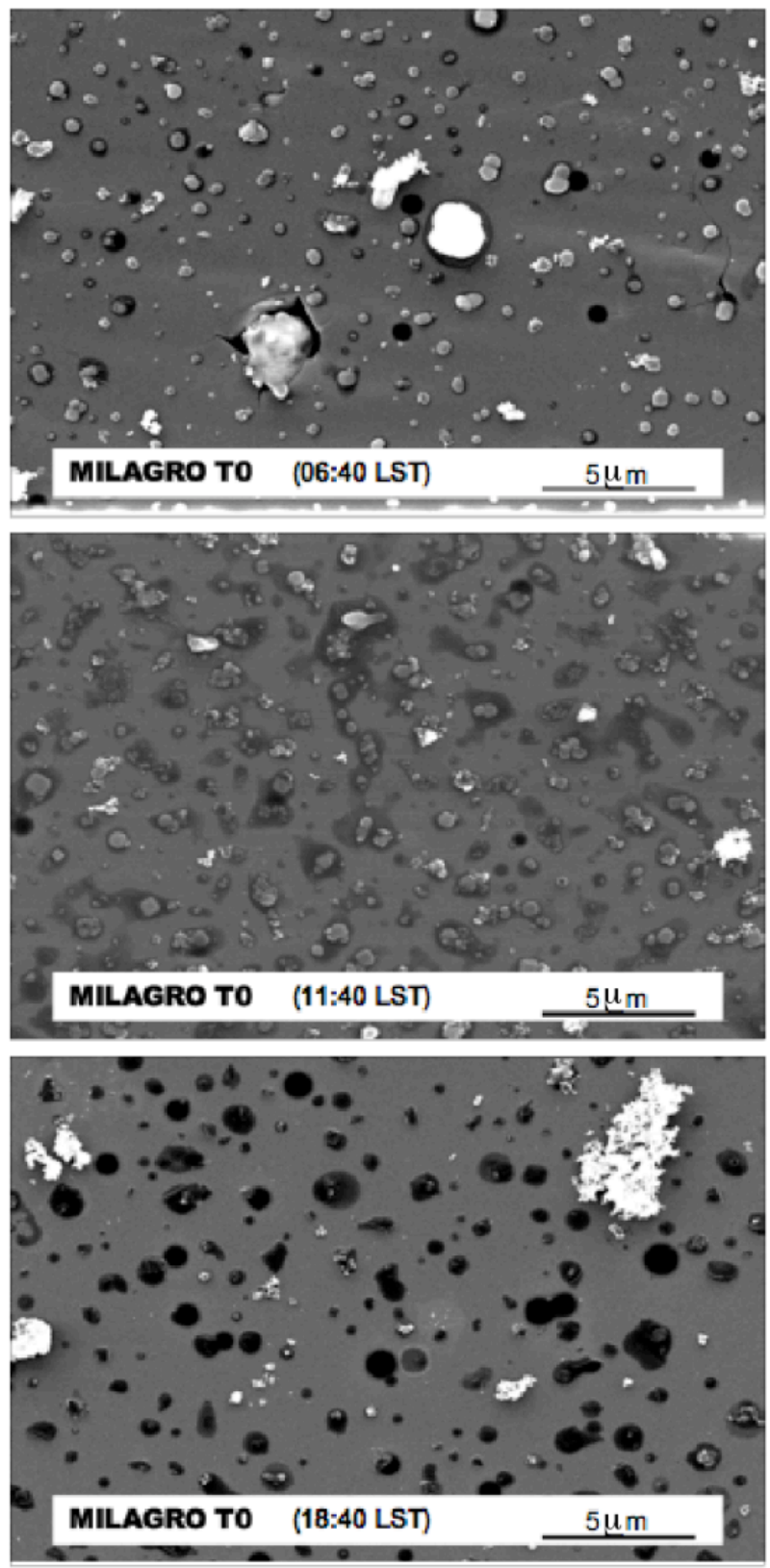

Fig. 11. SEM images of particles collected at the T0 sampling site at three times on 22 March. The darker areas around the particles indicate coating of particles by organic material during the daytime.

secondary organic material that condensed on already existing traffic emissions particles (D. Worsnop, private communication). Such behavior was found on numerous days during the MILAGRO campaign at all three sampling sites.

The measured OC/EC ratios at $\mathrm{T} 1$ also support this interpretation, showing a broad peak in the afternoon and much smaller values at night (Fig. 12). A minimum in the OC/EC ratio occurs in the 06:00-08:00 LST interval. This behavior is consistent with the finding of Baumgardner et al. (2007)

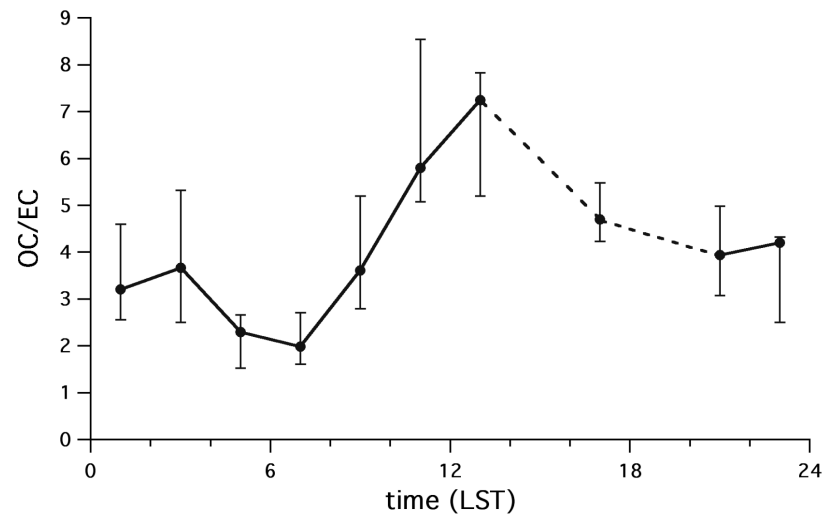

Fig. 12. Variation of median OC/EC ratio with time when MCMA fraction $\geq 0.55$ and median age $<12 \mathrm{~h}$ at $\mathrm{T} 1$. Dashed lines indicate missing values and vertical lines indicate 25 th and 75 th percentile values.

that the thinnest coating of non-light absorbing material was observed at the time of maximum concentrations of light absorbing carbon around 08:00 LST.

Our observations regarding the variation of $\alpha_{\mathrm{ABS}}$ with age should be treated with some caution. The numbers of samples in each category in the table are not large, especially during daylight hours, and the range of median particle ages that we could analyze was limited. The model results are also subject to uncertainty, as described earlier, and the data themselves have their own sources of potential error (e.g., Watson et al., 2005). Nonetheless we felt it would be interesting and potentially useful to present the features shown in Table 2. Our selection of conditions to analyze based on a threshold MCMA fraction of tracer particles $\geq 0.55$ is also somewhat arbitrary. A value of 0.55 for the MCMA fraction still allows a considerable influence from other sources such as biomass burning. We have looked at higher thresholds but the number of cases available for analysis decreases and the statistical significance also decreases. We also relaxed the criterion for MCMA fraction to allow more influence from non-MCMA sources. The principal difference we found was that as the percentage of the tracer particles attributed to biomass burning increased, the median ages of the tracer particles also increased, as was expected. In principle we could use model results to sort out the relative effects of particle age and MCMA or biomass burning fraction on $\alpha_{\mathrm{ABS}}$, but in practice our number of samples becomes too small to allow unambiguous results to be obtained.

\subsection{Change of $\alpha_{\mathrm{ABS}}$ between T1 and T2}

One of the objectives of the T1-T2 campaign was to examine changes in $\alpha_{\mathrm{ABS}}$ as the Mexico City urban plume was advected first over T1 and then over T2. The expectation was that if aerosols aged and became coated en route from $\mathrm{T} 1$ to $\mathrm{T} 2$, then those processes would result in measurable 
differences in $\alpha_{\mathrm{ABS}}$ between the two sites. Initial analyses (Doran et al., 2007; Doran, 2007) provided some evidence suggesting such changes had been observed but the statistical significance of the differences was not strong. Moreover, possible influences of biomass burning were recognized as a complicating factor that needed to be considered in greater detail, and for this paper we hoped that the results of our mesoscale modeling could provide additional insight. In light of the uncertainties in the modeling and measurements described earlier, we chose to restrict comparisons of the specific absorption of elemental carbon at the $\mathrm{T} 1$ and $\mathrm{T} 2$ sites to transport periods when the urban plume from the MCMA region was likely to have been a major contributor to the EC concentrations at both $\mathrm{T} 1$ and $\mathrm{T} 2$. These periods would be characterized in Fig. 9 by relatively high fractions of the tracer particles from MCMA sources and by relatively small values of the median ages of the ensemble of particles at each site. We also needed to strike a balance between the highly restrictive conditions for which the simulated biomass burning contributions are likely to have been very small (e.g., less than $20 \%$ of the tracer particles at a site) and having enough measurements of specific absorption to allow for reasonable size samples for comparison. In practice we settled on two criteria for identifying transport periods: 1) the computed MCMA fraction of the tracer particles at T2 was 0.4 or higher, and 2) the simulated median transport time at $\mathrm{T} 2$ was $6 \mathrm{~h}$ or less. These periods are indicated by the filled-in portions of the MCMA curve in the bottom panel of Fig. 9. Most of these cases are found around the period 18-21 March, and a comparison with the data presented in Fig. 2 shows that this period corresponded to a time interval during which both near-surface winds and winds aloft blew from the south southwest. We have also used a $10 \mathrm{~km} \times 10 \mathrm{~km}$ box surrounding $\mathrm{T} 2$ to calculate the MCMA fraction and median particle ages, and we found that the periods identified as favorable for T1-T2 comparisons are virtually the same as those found using the $5 \mathrm{~km} \times 5 \mathrm{~km}$ box.

The criteria used above to select "transport periods" are considerably more restrictive than the preliminary criteria used in our previous study (Doran et al., 2007), which were based on estimates of trajectories from the T1 profiler without regard to possible influences from biomass burning sources. In addition, for this study we further limited our analysis to times when specific absorption measurements were available at both $\mathrm{T} 1$ and $\mathrm{T} 2$ and the computed age of the particles at T2 was greater than that at T1. As a result the sample population has been reduced by more than a factor of two from our earlier analysis (to 23 cases), primarily because of the exclusion of periods with large contributions from biomass burning.

During these more restricted transport periods the median specific absorption of $\mathrm{EC}$ at $870 \mathrm{~nm}$ at $\mathrm{T} 1$ and $\mathrm{T} 2$ was 5.72 and $5.97 \mathrm{~m}^{2} \mathrm{~g}^{-1}$, respectively, but a Mann-Whitney test shows that the difference in the median values of $\alpha_{\mathrm{ABS}}$ at $\mathrm{T} 1$ and T2 was significant only around the $20 \%$ level. If we relax the 6-h restriction for the median age of the particles at $\mathrm{T} 2$ to $12 \mathrm{~h}$, there is no significant difference in the median specific absorption at the two sites even at the 50\% level. It is interesting to note that for all other times that do not include transport cases, the median values of $\alpha_{\mathrm{ABS}}$ decrease between $\mathrm{T} 1$ and $\mathrm{T} 2$, from 5.61 to $5.41 \mathrm{~m}^{2} \mathrm{~g}^{-1}$, but this difference is again not significantly different from zero at the $50 \%$ level.

An examination of individual cases shows that the differences in the calculated median ages of the tracer particles between $\mathrm{T} 1$ and $\mathrm{T} 2$ for transport conditions ranged approximately from 1 to $4 \mathrm{~h}$. Given the results from T1 shown earlier on the variation of $\alpha_{\mathrm{ABS}}$ with age, it is unclear why the specific absorption would increase during the relatively brief travel times between $\mathrm{T} 1$ and $\mathrm{T} 2$.

\subsection{Future studies}

At this point it is difficult to judge the importance of the small differences in $\alpha_{\mathrm{ABS}}$ between $\mathrm{T} 1$ and $\mathrm{T} 2$ without a measurement campaign of longer duration and perhaps a selection of locations with greater separation to provide additional data. For example, conditions favorable for transport between T1 and T2 also occurred on 9-11 March, before the full suite of instruments was operational at the two sites. Future campaigns lasting for two months or more would increase the number of cases with conditions favorable for analysis. The use of a mesoscale model with data assimilation to help analyze the results, as described here, would clearly be a valuable component of any such study.

Further evidence of the relative impacts of anthropogenic and biomass burning on particulates observed downwind from Mexico City should come from several aerosol mass spectrometers (AMS) that were deployed at ground sites (T0, T1, and mobile platforms) and on aircraft (G-1 and C130). Recently developed analysis methods for AMS organic spectra can separate organic mass into hydrocarbon-like (referred to as HOA) and oxygenated components (referred to as OOA). Zhang et al. (2005) and Volkamer et al. (2006) show that HOA and OOA correspond to primary and secondary organics, respectively. This analysis technique has been extended to include a category resulting from biomass burning (referred to as BBOA). The time variations of HOA, OOA, and BBOA at the surface sites and on the aircraft should allow identification of anthropogenic and biomass contributions to aerosols at $\mathrm{T} 1$ and $\mathrm{T} 2$ as well as information on how much coating of the aerosols occurred from secondary processes. The data on HOA, OOA, and BBOA components of the organic particulates are not yet available for this paper, but coupling that information with our analyses in the future would clearly be worthwhile. 


\section{Summary and conclusions}

We have used the WRF model, along with 4DDA, to simulate the local, regional, and synoptic meteorological conditions during the MILAGRO field campaign. The meteorological fields were used to drive a Lagrangian dispersion model, with tracer particles released at rates based on emission inventories for black carbon from anthropogenic sources and biomass burning. The results were used to identify periods when relatively fresh emissions from the MCMA were the primary contributors of EC at T1. They were then used to help examine the changes of the specific absorption, $\alpha_{\mathrm{ABS}}$, with time of day and with time after release. Coating of EC, with a consequent increase in $\alpha_{\mathrm{ABS}}$, appears to be limited during night. In contrast, coating proceeds rapidly during the day, with peak values of $\alpha_{\mathrm{ABS}}$ occurring in mid-afternoon. This interpretation is supported by SEM images of aerosols collected at the sampling sites and by measured OC/EC ratios at the $\mathrm{T} 1$ site.

Although $\alpha_{\mathrm{ABS}}$ increases during the day, strong evidence for increases of $\alpha_{\mathrm{ABS}}$ with particle age for median aerosol ages up to $6 \mathrm{~h}$ was not found. There was a small increase in $\alpha_{\mathrm{ABS}}$ between the T1 and T2 sites on days with conditions favorable for transporting the MCMA plume over the two sites, but the statistical significance of this result was marginal. For non-transport conditions the median values of $\alpha_{\mathrm{ABS}}$ at the T1 and T2 sites were essentially the same. Additional measurements taken over more extended time periods, perhaps with more widely separated sampling sites, would be valuable.

Acknowledgements. This research was supported by the Office of Science (BER), U.S. Department of Energy, under the auspices of the Atmospheric Science Program, under Contract DE-AC0576RL01830 at the Pacific Northwest National Laboratory. Pacific Northwest National Laboratory is operated for the U.S. DOE by Battelle Memorial Institute. We thank P. Arnott and G. ParedesMiranda of the Desert Research Institute for their PAS data, L. Kleinman of Brookhaven National Laboratory for the CO data from the G-1, and G. Huey of Georgia Institute of Technology for the CO data at T1. Finally, we thank D. Baumgardner for suggesting a possible source of the different values of $\alpha_{\mathrm{ABS}}$ in his and our studies.

Edited by: L. Molina

\section{References}

Andreae, M. O. and Gelencsér, A.: Black carbon or brown carbon? The nature of light-absorbing aerosols, Atmos. Chem. Phys., 6, 3131-3148, 2006,

http://www.atmos-chem-phys.net/6/3131/2006/.

Arnott, W. P., Moosmüller, H., Rogers, C. F., Jin, T., and Bruch, R.: Photoacoustic Spectrometer for Measuring Light Absorption by Aerosols: Instrument Description, Atmos. Environ., 33, 28452852, 1999.

Arnott, W. P., Moosmüller, H., Sheridan, P. J., Ogren, J. A., Raspert, R., Slaton, W. V., Hand, J. L., Kreidenweis, S. M., and Collett Jr., J. L.: Photoacoustic and filter-based ambient aerosol light absorption measurements: instrument comparisons and the role of relative humidity, J. Geophys. Res., 108, 4034, doi:10.1029/2002JD002165, 2003.

Barnard, J. C., Kassianov, E. I., Ackerman, T. P., Johnson, K., Zuberi, B., Molina, L. T., and Molina, M. J.: Estimation of a "radiatively correct" black carbon specific absorption during the Mexico City Metropolitan Area (MCMA) 2003 field campaign, Atmos. Chem. Phys., 7, 1645-1655, 2007,

http://www.atmos-chem-phys.net/7/1645/2007/.

Baumgardner, D., Raga, G. B., Kok, G., Ogren, J., Rosas, I., Báez, A., and Novakov, T.: On the evolution of aerosol properties at a mountain site above Mexico City, J. Geophys. Res., 105, $22243-$ 22 253, 2000.

Baumgardner, D., Raga, G., Peralta, O., Rosas, I., Castro, T., Kuhlbusch, T., John, A., and Petzold, A.: Diagnosing black carbon trends in large urban areas using carbon monoxide measurements, J. Geophys. Res., 107(D21), 8342, 10.1029/2001JD000626, 2002.

Baumgardner, D., Kok, G. L., and Raga, G. B.: On the diurnal variability of particle properties related to light absorbing carbon in Mexico City, Atmos. Chem. Phys., 7, 2517-226, 2007, http://www.atmos-chem-phys.net/7/2517/2007/.

Birch, M. E. and Cary, R. A.: Elemental carbon-based method for monitoring occupational exposures to particulate diesel exhaust, Aerosol Sci. Technol., 25, 221-241, 1996.

Bond, T. C. and Bergstrom, R. W.: Light absorption by carbonaceous particles: an investigative review, Aerosol Sci. Technol., 40, 27-67, doi:10.1080/02786820500421521, 2006.

Bond, T. C., Habib, G., and Bergstrom, R. W.: Limitations in the enhancement of visible light absorption due to mixing state, J. Geophys. Res., 111, D20211, doi:10.1029/2006JD007315, 2006.

Burtscher, H., Leonard, A., Steiner, D., Baltensperger, U., and Weber, A.: Aging of combustion particles in the atmosphere - results from a field study in Zürich, Water, Air, Soil Poll., 68, 137$147,1993$.

Chen, F. and Dudhia, J.: Coupling an advanced landsurface/hydrology model with the Penn State / NCAR MM5 modeling system. Part I: Model description and implementation, Mon. Weather Rev., 129, 569-585, 2001.

Chen S.-H. and W.-Y. Sun: A one-dimensional time dependent cloud model, J. Meteor. Soc Japan, 80, 99-118, 2002.

Chou, M.-D. and Suarez, M. J.: An efficient thermal infrared radiation parameterization for use in general circulation models, NASA Tech. Memo. 104606, 3, 85 pp., 1994.

Cleveland, W. S.: Robust locally weighted regression and smoothing scatterplots, J. Amer. Statist. Assoc., 74, 829-836, 1979.

Croft, B., Lohmann, U., and von Salzen, K: Direct Aerosol Forcing: Calculation from Observables and Sensitivities to Inputs, Atmos. Chem. Phys., 5, 1931-1949, 2005, http://www.atmos-chem-phys.net/5/1931/2005/.

Doran, J. C., Barnard, J. C., Arnott, W. P., Cary, R., Coulter, R. L., Fast, J. D., Kassianov, E. I., Kleinman, L. I., Laulainen, N. S., Martin, T. J., Paredes-Miranda, G. L., Pekour, M. S., Shaw, W. J., Smith, D. F., Springston, S. R., and Yu, X. Y.: The T1-T2 Study: Evolution of Aerosol Properties Downwind of Mexico City, Atmos. Chem. Phys., 7, 1585-1598, 2007, http://www.atmos-chem-phys.net/7/1585/2007/.

Doran, J. C.: Corrigendum to "The T1-T2 study: evolution of 
aerosol properties downwind of Mexico City" published in Atmos. Chem. Phys., 7, 1585-1598, 2007, Atmos. Chem. Phys., 7, 2197-2198, 2007, http://www.atmos-chem-phys.net/7/2197/2007/.

Fast, J. D, Gustafson Jr., W. I., Easter, R. C., Zaveri, R. A., Barnard, J. C., Chapman, E. G., and Grell, G. A.: Evolution of ozone, particulates, and aerosol direct forcing in an urban area using a new fully-coupled meteorology, chemistry, and aerosol model, J. Geophys. Res., 111, doi:10.1029/2005JD006721, 2006.

Fuller, K. A., Malm, W. C., and Kreidenweis, S. M.: Effects of mixing on extinction by carbonaceous particles, J. Geophys., Res., 104, 15 941-15 954, 1999.

Hong, S.-Y., Noh, Y., and Dudhia, J.: A new vertical diffusion package with an explicit treatment of entrainment processes, Mon. Weather Rev., 134, 2318-2341, 2006.

Jacobson, M. Z.: Isolating nitrated and aromatic aerosols and nitrated aromatic gases as sources of ultraviolet light absorption, J. Geophys. Res.-A, 104(D3), 3527-3542, 1999.

Jacobson, M. Z. and Seinfeld, J. H.: Evolution of nanoparticle size and mixing state near the point of emission, Atmos. Environ., 38, 1839-1850, 2004.

Johnson, K. S., Zuberi, B., Molina, L. T., Molina, M. J., Iedema, M. J., Cowin, J. P., Gaspar, D. J., Wang, C., and Laskin, A.: Processing of soot in an urban environment: case study from the Mexico City Metropolitan Area, Atmos. Chem. Phys., 5, 30333043, 2005, http://www.atmos-chem-phys.net/5/3033/2005/.

Kirchstetter, T. W., Novakov, T., and Hobbs, P. V.: Evidence that the spectral dependence of light absorption by aerosols is affected by organic carbon, J. Geophys. Res.-A, 109, D21208, doi:10.1029/2004JD004999, 2004.

Liu, Y., Bourgeois, A., Warner, T., Swerdlin, S., and Hacker, J.: Implementation of observation-nudging based on FDDA into WRF for supporting AFEC test operations, 6th WRF Conference, NCAR, Boulder, CO, 10.7, 2006.

Mallet, M., Roger, J. C., Despiau, J. P., and Dubovik, O.: A study of the mixing state of black carbon in urban zone, J. Geophys. Res., 109, D04202, doi:10.1029/2003JD003940, 2004.

Mann, H. B. and Whitney, D. R.: On a test of whether one of two random variables is stochastically larger than the other, Ann. Math. Stat., 18, 50-60, 1947.

Mlawer, E. J., Taubman, S. J., Brown, P. D., Iacono, M. J., and Clough, S. A.: Radiative transfer for inhomogeneous atmosphere: RRTM, a validated correlated-k model for the longwave, J. Geophys. Res., 102, 16 663-16 682, 1997.

Moteki, N., Kondo, Y., Miyazaki, Y., Takegawa, N., Komazaki, Y., Kurata, G., Shirai, T., Blake, D. R., Miyakawa, T., and Koike, M.: Evolution of mixing state of black carbon particles: Aircraft measurements over the western Pacific in March 2004, Geophys. Res. Lett., 34, L11803, doi:10.1029/2006GL028943, 2007.

Reid, J. S., Koppmann, R., Eck, T. F., and Eleuterio, D. P.: A review of biomass burning emissions part II: intensive physical properties of biomass burning particles, Atmos. Chem. Phys., 5, 799825,2005 http://www.atmos-chem-phys.net/5/799/2005/.

Riemer, N., Vogel, H., and Vogel, B.: Soot aging time scales in polluted regions during day and night, Atmos. Chem. Phys., 4, 1885-1893, 2004,

http://www.atmos-chem-phys.net/4/1885/2004/.
Sato, M., Hansen, J., Koch, D., Lacis, A., Ruedy, R., Dubovik, O., Holben, B., Chin, M., and Novakov, T.: Global atmospheric black carbon inferred from AERONET, Proc. Natl. Acad. Sci., 100, 6319-6324, 2003.

Sheridan, P. J., Arnott, W. P., Ogren, J. A., Anderson, B. E., Atkinson, D. B., Covert, D. S., Moosmuller, H., Petzold, A., Schmid, B., Strawa, A. W., Varma, R., and Virkkula, A.: The Reno aerosol optics study: An evaluation of aerosol absorption measurement methods, Aerosol Sci. Technol., 39, 1-16, 2005.

Skamarock, W. C., Klemp, J. B., Dudhia, J., Gill, D. O., Barker, D. M., Wang, W., and Powers, J. G.: A description of the advanced research WRF version 2. NCAR Technical Note, NCAR/TN486+STR, 88 pp., 2005.

Slowik, J. G., Cross, E. S., Han, J.-H., Davidovits, P., Onasch, T. B., Jayne, J. T., Williams, L. R., Canagaratna, M. R., Worsnop, D. R., Chakrabarty, R. K., Moosmüller, H., Arnott, W. P., Schwarz, J. P., Gao, R.-S., Fahey, D. W., Kok, G. L., and Petzold, A.: An Inter-Comparison of Instruments Measuring Black Carbon Content of Soot Particles, Aerosol Sci. Technol., 41, 3, 295-314, 2007.

Sokolik, I. N. and Toon, O. B.: Incorporation of mineralogical composition of aerosols into models of radiative properties of mineral aerosol from the UV to IR wavelengths, J. Geophys. Res.-A 104(D8), 9423-9444, 1999.

Stauffer, D. R. and Seaman, N.: Multiscale four-dimensional data assimilation, J. Appl. Meteor., 33, 415-434, 1994.

Stohl, A., Forster, C., Frank, A., Seibert, P., and Wotawa, G.: Technical note: The Lagrangian particle dispersion model FLEXPART version 6.2, Atmos. Chem. Phys., 5, 2461-2474, 2005, http://www.atmos-chem-phys.net/5/2461/2005/.

Volkamer, R., Jimenez, J. L., San Martini, F., Dzepina, K., Zhang, Q., Salcedo, D., Molina, L. T., Worsnop, D. R., and Molina, M. J.: Secondary organic aerosol formation from anthropogenic air pollution: Rapid and higher than expected, Geophys. Res. Lett., 33, L17811, doi:10.1029/2006GL026899, 2006.

Watson, J. G., Chow, J. C., Antony Chen, L.-W.: Summary of organic and elemental carbon/black carbon analysis methods and intercomparisons, Aerosol Air Qual. Res., 5, 65-102, 2005.

Wiedinmyer, C., Quayle, B., Geron, C., Beloe, A., McKenzie, D., Zhang, X., O'Neill, S., and Wynne, K. K.: Estimating emissions from fires in North America for air quality modeling, Atmos. Environ., 40, 3419-3432 2006.

Yokelson, R. J., Urbanski, S. P., Atlas, E. L., Toohey, D. W., Alvarado, E. C., Crounse, J. D., Wennberg, P. O., Fisher, M. E., Wold, C. E., Campos, T. L., Adachi, K., Buseck, P. R., and Hao, W. M.: Emissions from forest fires near Mexico City, Atmos. Chem. Phys., 7, 5569-5584, 2007, http://www.atmos-chem-phys.net/7/5569/2007/.

Zhang, Q., Worsnop, D. R., Canagaratna, M. R., and Jimenez, J. L.: Hydrocarbon-like and oxygenated organic aerosols in Pittsburgh: Insights into sources and processes of organic aerosols, Atmos. Chem. Phys., 5, 3289-3311, 2005, http://www.atmos-chem-phys.net/5/3289/2005/. 